\title{
USO DE BACILLUS SUBTILIS EM SUBSTRATO COMERCIAL PARA PRODUÇÃO DE MUDAS DE ESPÉCIES FLORESTAIS
}

\author{
Daniele Perreti Bettio, Fabio Fernando de Araújo \\ Universidade do Oeste Paulista - UNOESTE, Programa de Pós-Graduação em Agronomia, Presidente Prudente, SP. E- \\ mail: dpbettio@gmail.com
}

\section{RESUMO}

Objetivou-se com esse trabalho analisar o efeito da introdução de Bacillus subtilis em substrato comercial sobre o desenvolvimento de mudas de espécies florestais. O experimento foi conduzido em viveiro de mudas comercial. A rizobactéria foi formulada em pó na concentração de $1,010^{9}$ células por grama e foi misturada ao substrato em diferentes concentrações, cujos tratamentos obtidos foram: Testemunha $(0,0 \%) ; B$. subtilis $(0,5 \%) ; B$. subtilis $(1,0 \%) ; B$. subtilis $(2,5 \%)$ e $B$. subtilis (5,0\%). As espécies utilizadas foram Eucalyptus citriodora, Croton urucurana e Guazuma ulmifolia. As mudas foram conduzidas em tubetes dentro do viveiro. Após 120 dias as mudas foram coletadas para avaliações de altura e produção de biomassa. As doses de $B$. subtilis próximas de 3,0\% foram mais responsivas para aumento da altura de eucalipto e sangria d'água. $A$ produção de massa seca na raiz e parte aérea nas espécies florestais avaliadas, respondeu positivamente as maiores doses da rizobactéria incorporadas ao substrato.

Palavras-chave: Rizobactérias. Eucalipto. Reflorestamento. Biometria.

\section{BACILLUS SUBTILIS IN COMMERCIAL SUBSTRATES FOR PRODUCTION FOREST}

\begin{abstract}
The objective of this work to analyze the effect of the introduction of Bacillus subtilis in commercial substrate for the development of seedlings of forest species. The experiment was conducted in the seedling nursery Flora Victoria Regia in the municipality of Regente Feijó - SP. The rhizobacterium powder was formulated at a concentration of $1,010^{9}$ cells per gram, and the substrate was mixed in different concentrations, which were obtained treatments: Control $(0.0 \%)$; B. subtilis $(0,5 \%) ; B$. subtilis $(1,0 \%) ; B$. subtilis $(2,5 \%)$ and $B$. subtilis $(5,0 \%)$. The species used are Eucalyptus citriodora, Croton urucurana and Guazuma ulmifolia. After 120 days the seedlings collected for evaluation of height and biomass production. B. subtilis next doses of $3.0 \%$ were more responsive to increase and eucalyptus and water bleeding time. The dry matter yield in roots and shoots the assessed forest species, they responded positively to the highest doses of rhizobacteria used in the substrate.
\end{abstract}

Keywords: Rhizobacteria. Eucalyptus. Reforestation. Biometrics. 


\section{INTRODUÇÃO}

Atualmente são adotadas tecnologias para facilitar o manejo na produção de mudas para fins de reflorestamentos, tais como a utilização de tubetes, os quais apresentam menor diâmetro e ocupam menor espaço no viveiro, facilitando o transporte da ida ao campo e diminuindo os custos, tornando também mais dinâmico o processo de transplante das mudas para as covas (GOMES, et al.; 1985). Por fim, temos o uso de substrato que apresenta vantagens tais como, custos inferiores, capacidade de troca catiônica, aeração, maior uniformidade no desenvolvimento das mudas, retenção de umidade (BEZERRA; BEZERRA; 2000) e maior afinidade com o sistema radicular da planta (GOMES et al., 1985).

Entretanto, o sucesso em implantações de projetos de reflorestamento necessita que as plantas sejam bem formadas e estejam isentas de doenças para que se estabeleçam com maior desempenho no campo. Neste contexto, vem sendo estudada a utilização de rizobactérias promotoras de crescimento em plantas no momento da formação das mudas (CUNHA et al., 2013).

O uso excessivo e a utilização inadequada de defensivos agrícolas atingem diretamente o meio ambiente e estes impactos podem ser minimizados adotando-se inoculantes de rizobactérias promotoras de crescimento (RPCPs) (COELHO et al., 2007). Aumentos significativos na disponibilização de nutrientes para o vegetal, produção de fitohormônios e diminuição do crescimento de fitopatógenos na região rizosférica, são alguns dos benefícios que as rizobactérias proporcionam para as plantas (CASSIOLATO, 1996).

As espécies utilizadas neste trabalho são de suma importância no meio florestal. $\mathrm{O}$ Eucalyptus citriodora é uma espécie produtora de madeira de excelente qualidade usada em indústrias, além de plantios de florestas de monocultura, para a extração de óleo essencial das folhas (MORA e GARCIA; 2000). Croton urucurana, popularmente conhecida como sangria d'água, apresenta rápido crescimento e suas mudas são comercializadas para plantios pioneiros na recuperação de margens de rios que passaram por degradações (PAOLI; FREITAS; BARBOSA; 1995). E por fim, Guazuma ulmifolia também conhecida como mutambo, produz muitos derivados, tais como produtos madeireiros, gerando grande fonte de energia a partir de sua queima e produtos não madeireiros, como os frutos (utilizados para alimentação humana e de serventia medicinal), as fibras para fins têxteis, a extração de óleo e atualmente, também se enquadra como espécie arbórea nas recuperações ambientais, devido seu rápido estabelecimento (CARVALHO, 2007).

Portanto, o presente trabalho teve como objetivo avaliar o efeito da introdução da rizobactéria promotora de crescimento em plantas, Bacillus subtilis, ao substrato comercial para 
avaliar o desenvolvimento de mudas de Eucalyptus citriodora, Guazuma ulmifolia e Croton urucurana.

\section{METODOLOGIA}

O experimento foi conduzido no viveiro de produção de mudas Flora Vitória Régia que se encontra na Rodovia Raposo Tavares KM 555 no município de Regente Feijó - SP.

Foram utilizadas rizobactérias promotoras de crescimento em plantas da espécie Bacillus subtilis, formuladas em pó, na concentração de $1,010^{9}$ células por grama, disponibilizado pelo laboratório de Fitopatologia da Universidade do Oeste Paulista (UNOESTE), Presidente PrudenteSP.

As espécies arbóreas utilizadas no experimento foram de Eucalipto (Eucalyptus citriodora), Sangria d'água (Croton urucurana) e Mutambo (Guazuma ulmifolia). No preenchimento dos tubetes para o semeio das mesmas utilizou-se o substrato comercial BIOPLANT, indicado especificamente para ser utilizado em semeaduras de espécies florestais, o qual é composto por casca de pinus e alguns agregantes como,fibra de coco, casca de arroz, vermiculita e nutrientes para a planta.

As rizobactérias formuladas em pó foram misturadas ao substrato e posteriormente homegeneizadas. Definiram-se os seguintes tratamentos: T0 = Controle; T1 = 0,5\% de pó contendo rizobactérias no substrato; $\mathrm{T} 2$ = 1\% de pó contendo rizobactérias no substrato; T3 = 2,5\% de pó contendo rizobactérias no substrato; $\mathrm{T} 4=5 \%$ de pó contendo rizobactérias no substrato. Cada tubete recebeu um preenchimento médio de substrato úmido de 23 gramas.

No substrato previamente umedecido e acondicionado nos tubetes, realizou-se a semeadura: 10 sementes de eucalipto por tubete; 5 sementes de sangria d' água por tubete e 5 sementes de mutambo por tubete; numa profundidade rasa de aproximadamente $0,5 \mathrm{~cm}$. Os tubetes ficaram dispostos em bandejas com capacidade para 96 células. Estas ficaram suspensas em suportes de aço e mantidas em estufa.

O delineamento experimental foi fatorial inteiramente ao acaso representado por cinco tratamentos e três espécies (5x3), apresentando quatro repetições, considerando como uma unidade experimental um agrupamento de três plantas. Um mês após a semeadura, foi realizado o desbaste deixando apenas uma muda por tubete.

As plantas ficaram durante 90 dias na estufa, com irrigação periódica efetuada por sistema de aspersão e sombreadas com tela sombrite (50\%). Após essa data foram colocadas em área aberta para aclimatação e aos 120 dias após o plantio as plantas foram coletadas para as 
avaliações biométricas de massa seca da parte aérea e raiz, altura da parte aérea e comprimento de raiz.

As mudas foram retiradas dos tubetes e lavadas em água corrente para retirar o substrato aderido às raízes. Após a lavagem foram separadas em parte aéreas e raiz. Para mensuração da altura da parte aérea e comprimento de raiz das plantas se utilizou régua, separando-as e medindo de acordo com tratamento e repetição. Para avaliação da massa seca as plantas foram colocadas dentro de sacos de papéis e secas em estufa de $70^{\circ} \mathrm{C}$ por uma semana, após esse tempo foram pesadas em balança analítica de precisão.

Os resultados foram submetidos à análise de variância pelo Teste de Tukey de comparação de médias, ao nível de $5 \%$ de probabilidade e realizou à análise de regressão polinomial em relação às dosagens de Bacillus subtilis.

\section{RESULTADOS}

Pela análise de variância (Tabela 1) observa-se que todas as espécies responderam aos tratamentos, com resultados estatisticamente significativos. Os parâmetros matéria seca da parte aérea e da raiz apresentaram interações entre as doses e as espécies. A significância encontrada pelo teste de $\mathrm{F}$, na maioria dos parâmetros avaliados, demonstra o efeito positivo da introdução de Bacillus subtilis no substrato sobre o crescimento das espécies em estudo.

Tabela 1. Valores de F da análise de variância.

\begin{tabular}{lllll}
\hline F.V. & $\begin{array}{l}\text { Altura de } \\
\text { plantas }\end{array}$ & $\begin{array}{l}\text { Comprimento } \\
\text { de raiz }\end{array}$ & $\begin{array}{l}\text { M seca da p. } \\
\text { aérea }\end{array}$ & $\begin{array}{l}\text { M. seca de } \\
\text { raiz }\end{array}$ \\
\hline Espécie & $125,779^{* *}$ & $7,908^{* *}$ & $26,541^{* *}$ & $25,175^{* *}$ \\
Doses & $16,437^{* *}$ & $0,34 N S$ & $45,059^{* *}$ & $20,057^{* *}$ \\
Esp. $x$ Doses & 1,612 NS & $0,356 N S$ & $2,442^{*}$ & $2,690^{*}$ \\
\hline C.V. & 13,86 & 5,84 & 22,94 & 22,95 \\
\hline
\end{tabular}

*5\% de probabilidade ** $1 \%$ de probabilidade

Com relação à altura de plantas, pela análise de regressão (Figura 1), pode ser constatado um ajuste quadrático para as doses empregadas nas três espécies, com destaque maior para o eucalipto e a sangria d' água. Analisando-se as curvas obtidas pode-se observar que o ponto de máximo situa-se nas doses entre 3,0 a 4,0\% da bactéria no substrato. Nota-se que após a dosagem de $5,0 \%$ os incrementos na altura das mudas dessas duas espécies, tendem a um decréscimo no desenvolvimento da parte aérea. 


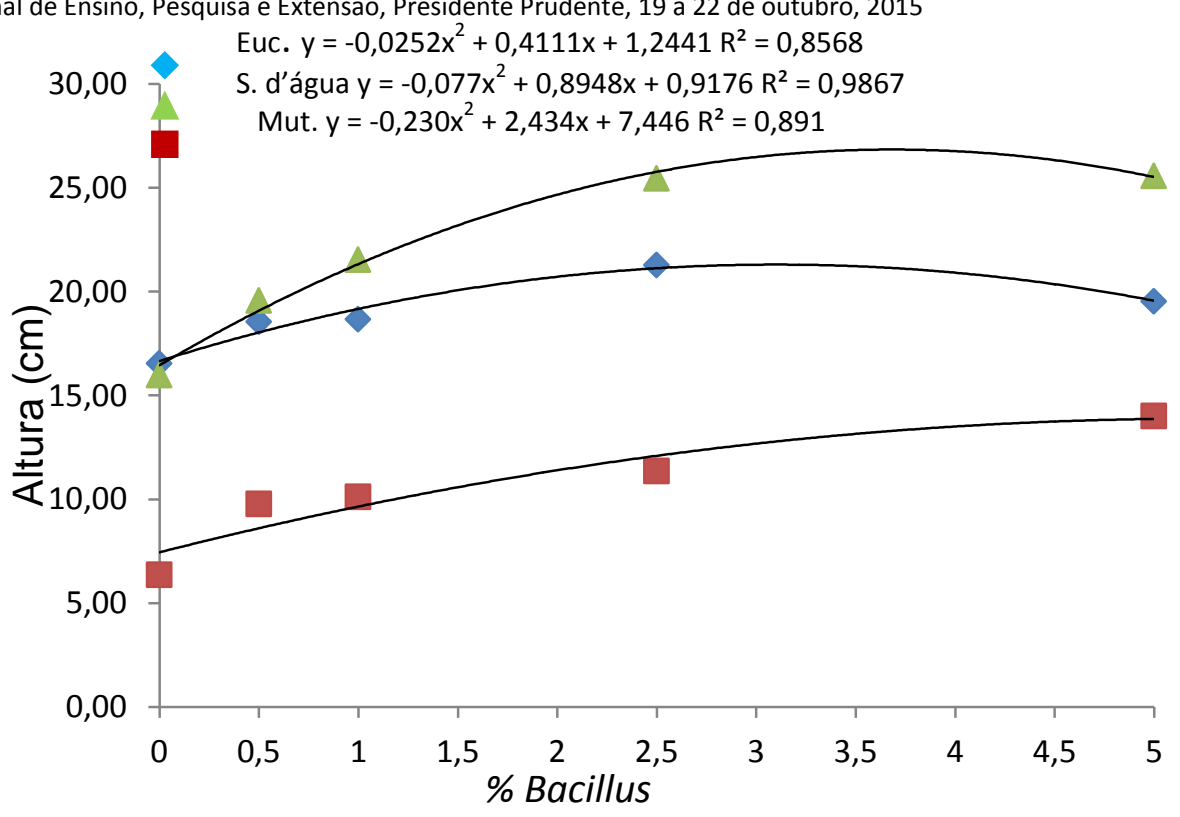

Figura 1. Análise de regressão da avaliação da altura de plantas nas três espécies em função da aplicação de doses de Bacillus subtilis.

Observa-se também que ocorreram ajustes quadráticos no ganho de massa seca da parte aérea, pela análise de regressão (Figura 2). Porém, o ponto de máximo, que representa maiores ganhos de matéria seca das espécies, de acordo com a tendência da poligonal que o demonstra, pode estar próximo ou acima dos 5,0\%, avaliado como maior dose nesse estudo.

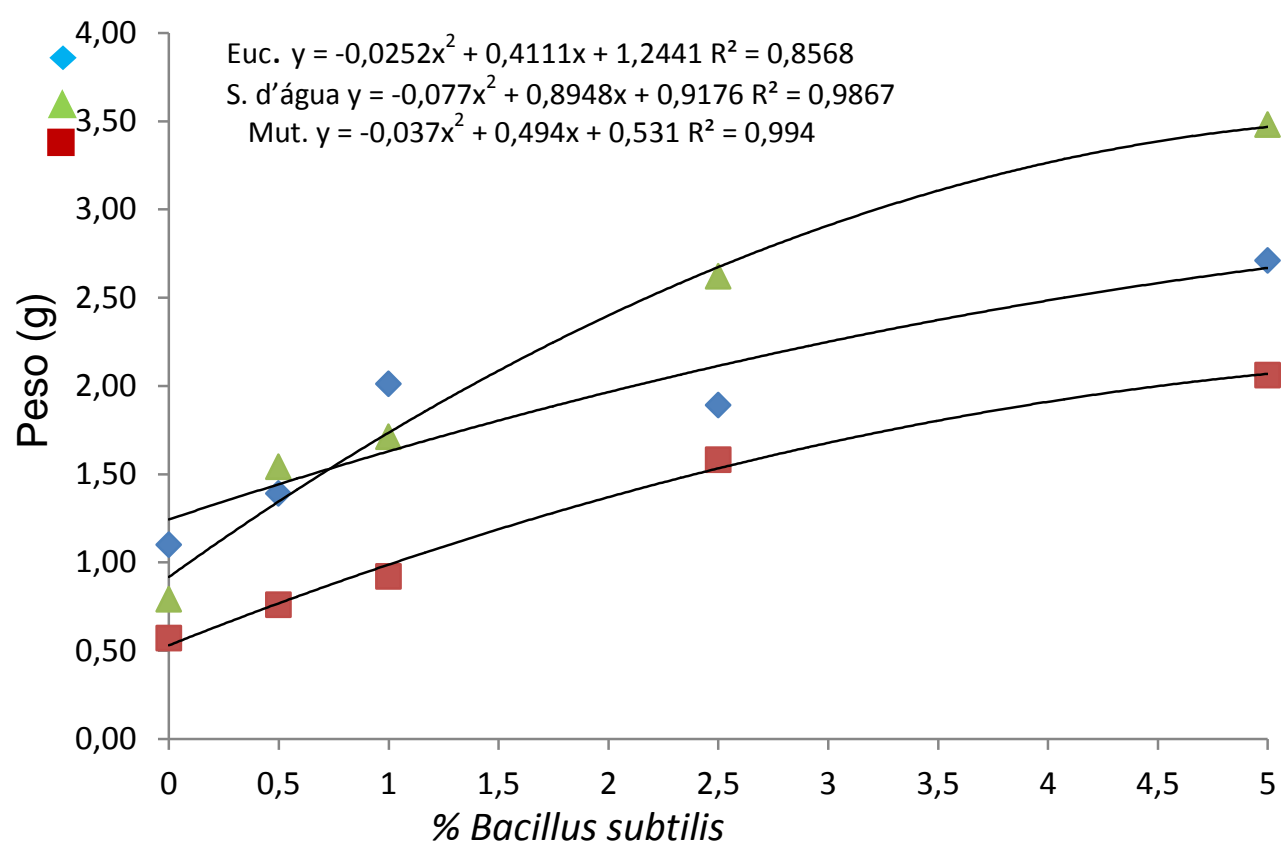

Figura 2. Análise de regressão da avaliação do peso de matéria seca da parte aérea de plantas nas três espécies em função da aplicação de doses de Bacillus subtilis. 
Com relação à quantificação de massa seca da raiz, as diferentes doses de Bacillus subtilis surtiram efeitos expressivos nas espécies mutambo e sangria d'água. Entretanto, de acordo a análise de regressão (Figura 3), o ajuste quadrático demonstrado pelas três espécies em estudo, de acordo com a linha de tendência, evidencia que o ponto máximo de ganhos está acima da dose de $5,0 \%$. Assim, incrementos nas doses do Baciilus subtilis ao substrato sugerem maiores aumentos em produção de matéria seca de raiz pelas plantas.

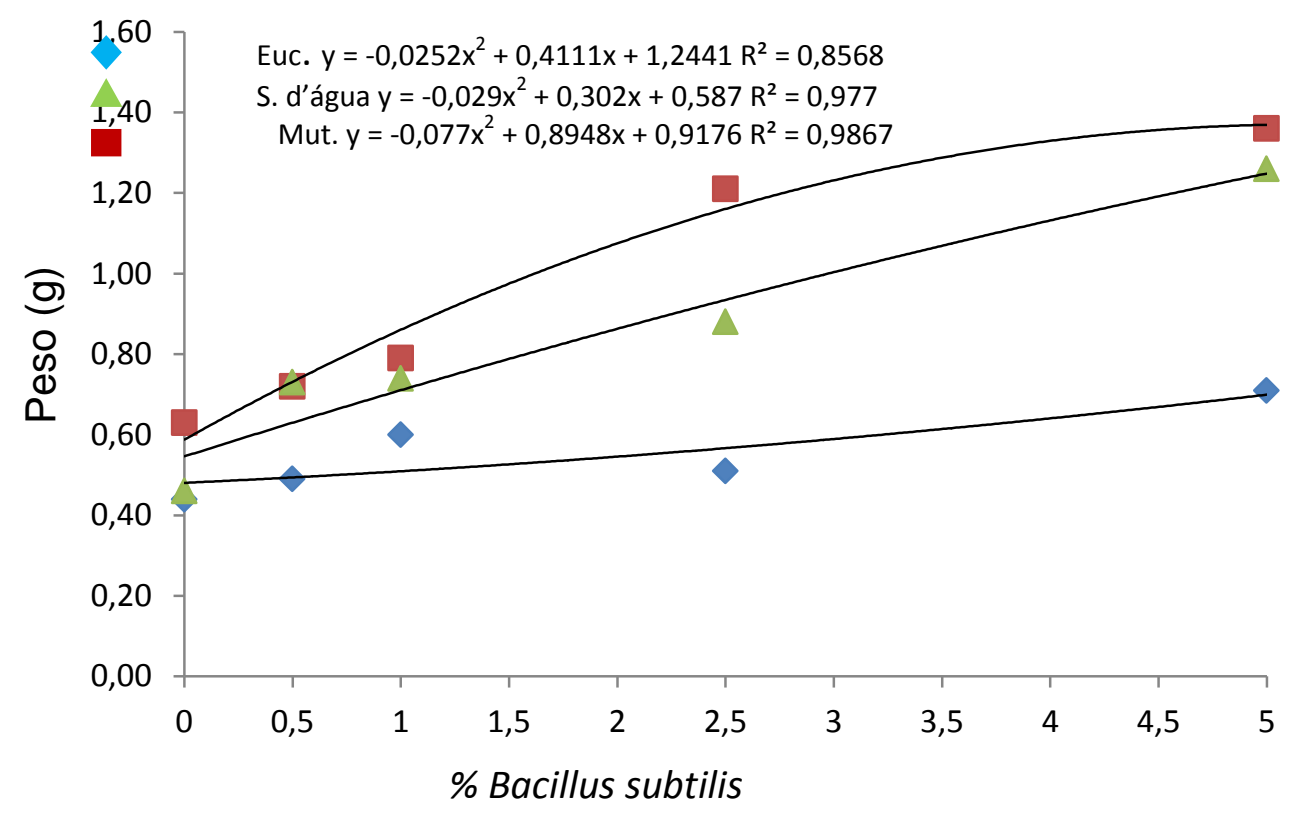

Figura 3. Análise de regressão da avaliação da matéria seca da raiz de plantas nas três espécies em função da aplicação de doses de Bacillus subtilis.

A utilização de Bacillus subtilis no substrato para produção de mudas mostrou-se como uma tecnologia promissora para o segmento de reflorestamento. Os ganhos encontrados nesta etapa podem ainda ser refletidos no campo, necessitando-se novos trabalhos para comprovação dos benefícios nesta etapa.

\section{DISCUSSÃO}

De maneira semelhante aos resultados obtidos nesse trabalho, ao utilizar espécies florestais, Brunetta et al., (2010), ao isolar bactérias do gênero Bacillus spp. na região rizosférica do solo sob Pinus taeda, constatou que alguns isolados incrementaram significativamente de 10 a 16\% a altura da espécie. Outros resultados promissores também foram obtidos quando Araújo (2008) inoculou sementes de milho com Bacillus subtilis formulado com farinha de ostras e obteve ganho significativo em altura das plantas de até $134 \%$. Ressalta-se uma relação indireta desses dados de crescimento em altura das plantas, com a capacidade das rizobactérias em produzirem hormônios de crescimentos (HARTHMANN, 2010). 
Os resultados obtidos se consolidam com outros encontrados na literatura, tais como o de Moreira e Araujo (2013), que verificaram através de isolados de Bacillus subtilis ganhos variados entre 53 a $167 \%$ na produção de massa seca da parte aérea da espécie Eucalyptus urograndis. Já em estudos com Sibipiruna, foram demonstrados ganhos de até $27,2 \%$ na massa seca da parte aérea das plantas (CUNHA et al., 2013). Dentre os mecanismos das rizobactérias, merece ser destacada a capacidade que o Bacillus subtilis pode exercer como agente de fixação de nitrogênio nas plantas. Foi constatado que o Bacillus spp. tem como contribuição uma fixação

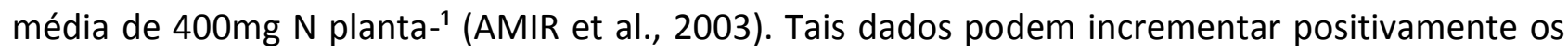
ganhos no peso da matéria seca da parte aérea das plantas, já que pode promover aumento da área foliar (LANNA FILHO; FERRO; PINHO, 2010).

Em outro trabalho realizado com Eucalyptus spp., isolados de rizobactérias se monstraram eficientes ao promoverem ganhos de até $250 \%$ em quantificação do peso da matéria seca do sistema radicular (TEIXEIRA et al., 2007). Resultados semelhantes foram obtidos com sibipiruna (CUNHA et al., 2013) e Pinus taeda (BRUNETTA et al., 2007). Condições estruturais do solo ou substrato em que as mudas são plantadas exercem papel fundamental em maiores taxas de desenvolvimento do sistema radicular das plantas, além dos benefícios que o Bacillus subtilis fornece ao crescimento das raízes por sua capacidade em sintetizar fito-hormônios (LANNA FILHO; FERRO; PINHO; 2010).

\section{CONCLUSÃO}

A introdução de Bacillus subtilis ao substrato proporcionou desenvolvimentos significativos em todas as espécies, variando conforme dosagens e parâmetros avaliados. As doses de B. subtilis próximas de 3,0\% foram mais responsivas para aumento da altura de eucalipto e sangria d'água. A produção de massa seca na raiz e parte aérea nas espécies florestais avaliadas respondeu positivamente as maiores doses da rizobactéria utilizadas no substrato.

\section{REFERÊNCIAS}

AMIR, H. G.; SHAMSUDDIN, Z. H.; HALIMI, M. S.; RAMLAN, M. F.; MARZIAH, M. N2 fixation, nutrient accumulation and plant growth promotion by rhizobacteria in association with oil palm seedlings. Pakistan Journal of Biological Sciences, Faisalabad, v. 6, p. 1269-1272, 2003. http://dx.doi.org/10.3923/pjbs.2003.1269.1272

ARAUJO, FABIO FERNANDO DE. Inoculação de sementes com Bacillus subtilis, formulado com farinha de ostras e desenvolvimento de milho, soja e algodão. Ciênc. Agrotec., Lavras, v. 32, n. 2, Apr. 2008. 
BEZERRA, F. C.; BEZERRA, G. da S. S.; Efeito do substrato na formação de mudas de meloeiro (Cucumis melo). Embrapa Agroindústria Tropical, 2000.

BRUNETTA, J. M. F. C. et al. Isolamento e seleção de rizobactérias promotoras do crescimento de Pinus taeda. Revista Árvore, v. 34, n. 3, p. 399-406, 2010. http://dx.doi.org/10.1590/S0100$\underline{67622010000300003}$

CARVALHO, P. E. R; Mutamba, Guazuma ulmifolia. Circular Técnica 141. EMBRAPA. Colombo, PR. Nov., 2007.

CASSIOLATO, A. M. R.; Seleção de rizobactérias promotoras de crescimento de plantas de araruta (Maranta arundinacea I.). 1996.

COELHO, L. F.; FREITAS, S.S.; MELO, A. M. T. AMBROSANO, G. M. B.; Interação de bactérias fluorescentes do gênero Pseudomonas e de Bacillus spp. com a rizosfera de diferentes plantas. Revista Brasileira de Ciência do Solo, v. 31, 2007.

CUNHA, JEANE DE FÁTIMA et al. Potencial de rizobactérias no crescimento de mudas de sibipiruna (Caesalpinia peltophoroides Benth). 2013.

GOMES, J. M.; COUTO, L.; PEREIRA, A. R.; USO DE DIFERENTES SUBSTRATOS NA PRODUÇÃO PE MUDAS DE Eucalyptus granais EM TUBETES E EM BANDEJAS DE ISOPOR1. Revista Árvore, v. 9, n. 1, p. 58, 1985.

HARTHMANN, Oscar Emilio Ludtke et al. Rhizobacteria on the production and yield of onion. Ciência Rural, v. 40, n. 2, p. 432-435, 2010.

LANNA FILHO, ROBERTO; FERRO, HENRIQUE MONTEIRO; DE PINHO, RENATA SILVA CANUTO. Controle biológico mediado por Bacillus subtilis. Revista Trópica: Ciências Agrárias e Biológicas, v. 4, n. 2, 2010.

MORA, ADMIR LOPES; GARCIA, CARLOS HENRIQUE. A cultura do eucalipto no Brasil. 2000.

MOREIRA, Ana Ligia de Lima; ARAÚJO, Fabio Fernando de. Bioprospecção de isolados de Bacillus spp. como potenciais promotores de crescimento de Eucalyptus urograndis. 2013.

PAOLI, ADELITA AS; FREITAS, LEANDRO; BARBOSA, JOSÉ MARCOS. Caracterização morfológica dos frutos, sementes e plântulas de Croton floribundus Spreng. e de Croto urucurana Baill.(Euphorbiaceae). Revista Brasileira de sementes, v. 17, n. 1, p. 57-68, 1995. http://dx.doi.org/10.17801/0101-3122/rbs.v17n1p57-68

TEIXEIRA, D. A.; ALFENAS, A.C.;MAFIA, R. G.; MAFFIA, L. A.; FERREIRA, E. M.; Evidências de indução de resistência sistêmica à ferrugem do eucalipto mediada por rizobactérias promotoras do crescimento de plantas. Fitopatologia Brasileira, v. 30, n. 4, p. 350-356, 2005. http://dx.doi.org/10.1590/S0100-41582005000400003 